
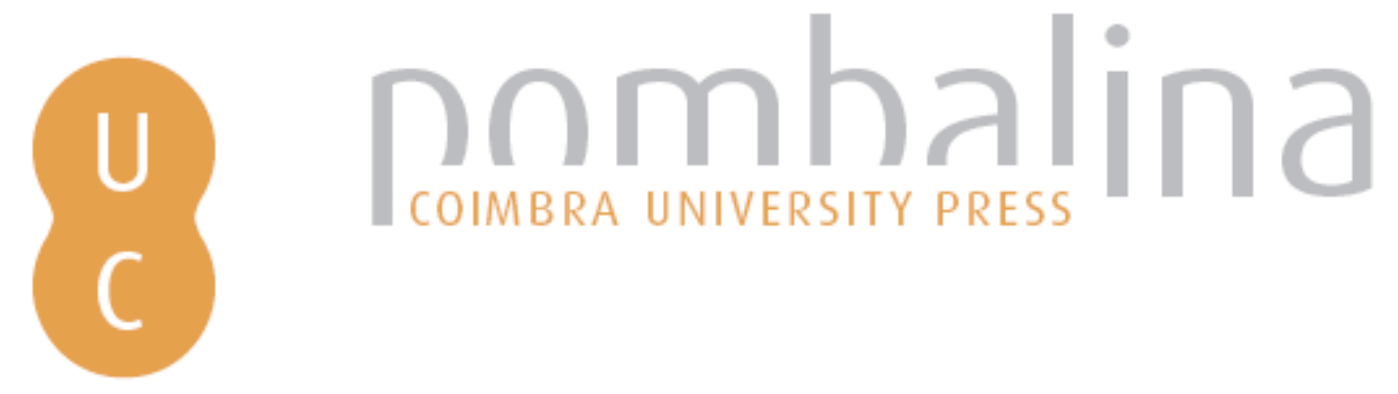

\title{
Redes sociales y periodismo: las puertas, de par en par
}

Autor(es): $\quad$ Luis Cebrián, Juan

Publicado por: Imprensa da Universidade de Coimbra

URL

persistente: URI:http://hdl.handle.net/10316.2/36653

DOI: $\quad$ DOI:http://dx.doi.org/10.14195/978-989-26-0873-0_15

Accessed : $\quad$ 26-Apr-2023 16:13:54

A navegação consulta e descarregamento dos títulos inseridos nas Bibliotecas Digitais UC Digitalis, UC Pombalina e UC Impactum, pressupõem a aceitação plena e sem reservas dos Termos e Condições de Uso destas Bibliotecas Digitais, disponíveis em https://digitalis.uc.pt/pt-pt/termos.

Conforme exposto nos referidos Termos e Condições de Uso, o descarregamento de títulos de acesso restrito requer uma licença válida de autorização devendo o utilizador aceder ao(s) documento(s) a partir de um endereço de IP da instituição detentora da supramencionada licença.

Ao utilizador é apenas permitido o descarregamento para uso pessoal, pelo que o emprego do(s) título(s) descarregado(s) para outro fim, designadamente comercial, carece de autorização do respetivo autor ou editor da obra.

Na medida em que todas as obras da UC Digitalis se encontram protegidas pelo Código do Direito de Autor e Direitos Conexos e demais legislação aplicável, toda a cópia, parcial ou total, deste documento, nos casos em que é legalmente admitida, deverá conter ou fazer-se acompanhar por este aviso.

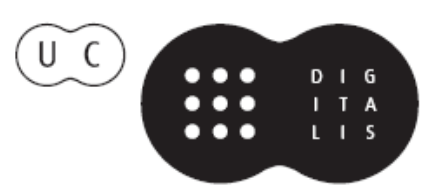


www.uc.pt/ imprensa_uc CONTACTO imprensa@uc.pt VENDAS ONLINE http://livrariadaimprensa.uc.pt JANEIRO 2015
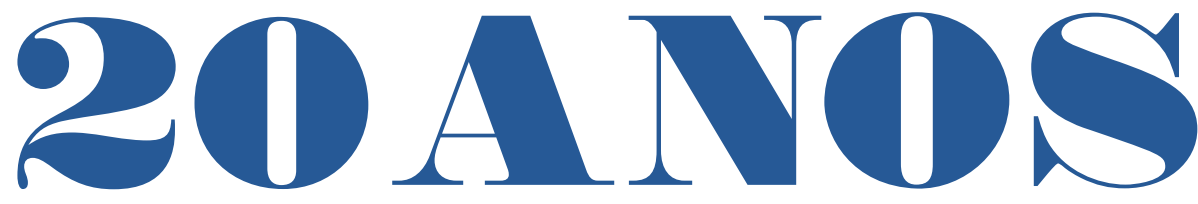

\section{DE JORNALISMO CONTRA A INDIFERENÇA}

TEXTOS DE

Marc Lits, Adriano Duarte Rodrigues, Tito Cardoso e Cunha, José Augusto Mourão, Alberto Pena Rodríguez, Maria Augusta Babo, Daniel Cronu, João Pissarra Esteves, Gilles Gauthier, Heloísa Paulo e Luís Reis Torgal, Alfredo Barroso, António Fidalgo, Nöel Nel, João de Almeida Santos, Juan Luis Cebrián, António Dias Figueiredo, Marina Themudo, Jorge Sampaio, Nelson Traquina, Mário Soares
( livro que agora se apresenta, nasce de dois desígnios fundamentais: por um lado, celebrar duas décadas de ensino do Jornalismo na Universidade de Coimbra e, por outro, partilhar com um público mais alargado um conjunto de reflexões sobre os media, o jornalismo, a comunicação e o espaço público.

Se o ensino superior do Jornalismo em Portugal, relativamente tardio em relação ao resto da Europa, deu os seus primeiros passos no fim dos anos 70 do século passado, ele aparece apenas duas décadas depois na academia coimbrã. Contudo, esta foi, no contexto nacional, a primeira licenciatura em Jornalismo, distinguindo-se, quer em título, quer em objetivos, das licenciaturas então existentes no país. A criação de uma Licenciatura em Jornalismo na Universidade de Coimbra, em 1993-1994, foi, por si, um acontecimento. Com efeito foi necessário que reitor, professores e jornalistas ousassem atualizar a oferta curricular da Faculdade de Letras, oferecendo um curso há muito desejado pela sociedade e pelo mercado, embora desconsiderado por alguns setores da academia. Correndo o risco de omitir alguém, a quem antecipadamente pedimos desculpa, não podemos deixar de recordar os esforços dos jornalistas João Mesquita, João Fonseca, em representação
Todas as gerações, sem dúvida, se julgan para refazer o mundo. A minha sabe, nc que não poderá refazê-lo. A sua tarefa é tc

Consiste em impedir que se desfaça, $p$ unicamente das suas negações A. Camus, Discursos da Suécia (1957)

do Sindicato dos Jornalistas, e de Jorge Castilho, a quem mais tarde se viria associar o nome de Mário Martins, bem como o do então Reitor da Universidade de Coimbra Rui Alarcão, e dos professores João Roque e Luís Reis Torgal. Entre 1993 e 1996, a Licenciatura em Jornalismo funcionou com um Secretariado, que teve um papel executivo e científico nos primeiros tempos do curso na FLUC. Presidido pelo Presidente do Conselho Científico Ludwig Scheidl, este 


\title{
Redes sociales y periodismo: las puertas, de par en par*
}

\author{
Juan Luis Cebrián
}

Administrador da Prisa

Dice Erasmo en su elogio de la estulticia que "el espíritu humano está hecho de tal manera que llega con mayor facilidad a la ficción que a la realidad", de modo que si en un sermón "se habla de algo trascendental y profundo, la gente bosteza, se aburre, y acaba durmiéndose; pero si el clamador (perdón, se corrige el propio Erasmo, quería decir el orador) comienza contando un cuento de viejas, todos se espabilan, atienden, y siguen el sermón con un palmo de boca abierta”. Ese miedo escénico al aburrimiento del auditorio me lleva a repetir el ruego habitual de Gabriel García Márquez cuando iniciaba sus no muy frecuentes intervenciones públicas: que quienes decidan ausentarse de la sala, lo hagan con cuidado y en silencio para no despertar a los que estén dormidos.

Pertenezco a una generación de españoles que creció leyendo a hurtadillas al poeta Miguel Hernández, prohibido por la dictadura y cuyo centenario celebramos hace un par de años. Las cárceles franquistas se estremecieron con sus cantos, entonados por los presos políticos: "Vientos del pueblo me llevan, vientos del pueblo me arrastran, me parten el corazón y me aventan la garganta". Hoy ese vendaval es cibernético y tecnológico, y hace que nuestros corazones se hinchen de emoción, mientras nuestras cabezas crepitan atribuladas, ante la suposición de que efectivamente, una vez más en el devenir de los tiempos, estamos hablando de entregar al pueblo el poder. Lo primero que se me ocurre es que si alguien se ha planteado algo semejante es porque cree que el pueblo todavía no lo tiene, o no lo tenía, en contra de lo que podíamos suponer desde la implantación de la democracia. Lo segundo, que nos encontramos en una coyuntura histórica en que es preciso poner a revisión algunos dogmas propios de esa misma democracia representativa. Aunque, como Churchill, sigo pensando que siendo el peor régimen del mundo es, por el momento, el menos malo de los conocidos.

No trato desde luego de dar respuesta con mi intervención a semejantes grandes cuestiones. Poder y pueblo son sustantivos mayores que inspiran a los poetas y estremecen a los políticos. La literatura sobre el Poder podría lle-

\footnotetext{
* Conferência proferida na FLUC em 2012.
} 
nar varios recintos del tamaño de la biblioteca de Alejandría. Max Weber lo definía como "la probabilidad de imponer la propia voluntad dentro de una relación social, aun contra toda resistencia” y Georges Bourdeau señalaba que "el poder es una fuerza al servicio de una idea". El profesor Duverger entiende que el poder se refiere a la dominación de unos hombres sobre otros y Charles Wrigth Mills, en su ensayo sobre Política, Pueblo, Poder, asegura que la forma última de éste es la coacción, aunque se sirve también de la autoridad y la manipulación. Todos estos teóricos, y muchos otros que me dejo en la trastienda, insisten en que el poder se caracteriza por su efectividad, es decir, su potencial de dominación, y también por su estructura interna, su jerarquización y organización, y por la capacidad que tienen de influir en él los diferentes estamentos sociales, los lobbies y grupos de presión. Entre ellos, sin duda alguna, es preciso contar con los medios de comunicación, que recibieron el calificativo de cuarto estamento durante la revolución Francesa, y que han pasado a la historia, sobre todo en lo que se refiere a la prensa, precisamente con el apelativo de cuarto poder.

Los periódicos, tal y como han llegado hasta nuestros días, forman parte de la institucionalidad que la democracia representativa alumbró en los albores del siglo XIX. A quienes están acostumbrados a mirar los diarios como un "antipoder", en expresión del antiguo presidente de la república francesa Valéry Giscard D’Estaing, les provoca no poca confusión y desasosiego comprobar que las grandes empresas dedicadas a la prensa y los medios de comunicación forman parte de esa realidad institucional que facilita el consenso necesario sobre el que se edifican las democracias. Dicho consenso se elabora precisamente a través de la opinión pública. El papel singular que los diarios (y más tarde las radios y las televisiones) han jugado en la formación de la misma es lo que ha hecho que, durante siglos, los periodistas viviéramos la esquizofrenia de pertenecer a la institucionalidad de los poderes al tiempo que provocábamos en ocasiones su fractura. Lo hacíamos, lo hacemos todavía, a base de publicar informaciones u opiniones que ponen en entredicho la transparencia de su actuación y la solidez de las bases sobre las que se sustentan. Quienes nos dedicamos a hacer diarios nos convertimos en mediadores entre la realidad y nuestros lectores, igual que los diputados lo son entre la autoridad y quienes les eligen. Todo esto ha funcionado así más o menos durante doscientos años. Hasta que el avance imparable de la sociedad de la información ha puesto de relieve las carencias no solo de nuestra industria, sino de la arquitectura política que contribuye a sujetar. Esta se resiente cada vez más, hasta el punto de amenazar ruina. La prensa, 
como espina dorsal de las democracias, se encuentra ahora en medio de una lucha de supervivencia. No se trata, como en otras ocasiones, de que padezcamos una crisis coyuntural o de la necesidad de acoplarnos a los nuevos tiempos y servirnos de las nuevas técnicas. Nos encontramos ante un cambio de paradigma que ha trastocado el orden de los valores y el entendimiento de la realidad. Un cambio, lo he repetido muchas veces, equiparable al que se generó tras la invención de la imprenta. Entonces, la cultura salió de los monasterios, se liberalizó el pensamiento (el mejor ejemplo de ello fue la libre interpretación de los libros sagrados), se extendió la enseñanza, se potenció el comercio, ayudado por los descubrimientos de nuevos territorios: en definitiva, cambió la naturaleza del poder y su distribución.

Cada gran invención, cada aportación científica o tecnológica que ha conocido la humanidad se inscribe bajo el común denominador de la proliferación de nuevos poderes y su eventual democratización. "Empowering the people”, dar el poder al pueblo, es el resultado de la expansión del ferrocarril, gracias a la máquina de vapor; de la multiplicación de las comunicaciones, gracias al telégrafo y a los estudios sobre electromagnetismo; de la generalización del uso de la energía; o de la construcción de los medios de comunicación de masas, una vez que supimos cómo utilizar las ondas hertzianas. De cada uno de esos eventos se derivaron transformaciones profundas del comportamiento humano, tanto individual como colectivo. Y en cada una de esas ocasiones la autoridad competente, que siente amenazados sus privilegios, sus aptitudes para coaccionar y manipular, se resistió al cambio, muchas veces hasta patas arriba, como hacen los insectos temerosos de sufrir un aplastamiento.

La aparición de Internet y la extensión de la cultura digital sugieren consecuencias para nuestras vidas de igual o mayor tamaño que las derivadas del invento de Gutenberg. Los desafíos y las amenazas que para el futuro de los medios constituyen solo son un aspecto de los cambios estructurales que el mundo ha comenzado a experimentar. Desde la articulación de la economía financiera al desarrollo de la investigación científica no hay actividad humana que no se vea sacudida en sus cimientos por lo que podríamos llamar el ataque de los algoritmos y los bytes. Nos encontramos ante una auténtica revolución, todavía en sus albores, que como todas las revoluciones que en el mundo han sido promete entregar el poder a los pueblos. Como todas también, es una revuelta violenta y bañada en sangre: ha comenzado a plagar de víctimas el paisaje de nuestras sociedades y ha engendrado una nueva clase política y económica, una nueva elite, destinada a liderar el proceso, a 
asumir y controlar el poder que se entrega a los ciudadanos, administrándolo a su albedrío.

No obstante, una parte de ese poder mismo parece haberse depositado de manera directa y para siempre en manos de las gentes. Aunque quizás estas se hallen deslumbradas por la fulgurante apariencia de las capacidades que encierra y no seamos conscientes, no lo bastante, de la emergencia de esa nueva clase dirigente que aspira, incluso sin saberlo, a una especie de control universal. Enseguida hablaré de las paradojas y contradicciones que estimula la sociedad digital, pero es preciso reconocer que, en principio, esta es más participativa e igualitaria que la que ahora denominamos analógica. Cientos, miles, millones ya, de ejemplos ilustran este nuevo empoderamiento de los ciudadanos gracias al uso de las nuevas tecnologías, que les permite hacer frente a la autoridad constituida, absorta y sin respuestas ante los nuevos retos. Abundan los ejemplos de cómo el asalto a la Bastilla digital por parte de las masas enardecidas es imposible de contener mediante medios primordialmente analógicos como los que utilizan aún la mayoría de los gobiernos. Lo pone de relieve lo sucedido durante la primavera árabe, que ha terminado por convertirse en un otoño caliente y amenaza con devenir en frío invierno.

Hay quien considera este tipo de demostraciones como el fruto de la acción de "multitudes inteligentes", en la infeliz definición del analista Howard Rheingold. Porque reúnen - dice - a "gente capaz de actuar en conjunto a pesar de que no conocerse entre sí". Los mensajes de texto, los twiters y os muros de las redes sociales provocan un gran entusiasmo en todo el mundo y han servido en muchas ocasiones para organizar gigantescas manifestaciones populares de todo tipo, en cierta medida convocadas por generación casi espontánea. Los activistas de los movimientos sociales de nuestro siglo utilizan con tino y habilidad los avances tecnológicos para sus reivindicaciones. Los gobiernos tratan inútilmente de ponerles coto. Autoridades de países como China, Birmania e Irán acuden para ello al bloqueo del acceso a los mensajes de texto e Internet o decretan un apagón temporal de los teléfonos móviles. Pero todo parece insuficiente a la hora de contener la ola digital. Mensajes instantáneos, whatsaps, correos electrónicos, twiters, páginas webs, blogs, y todo el resto de la flora y fauna digital, son un método de hacer negocios, de escribirse misivas de amor, de convocar a la revolución de ensalzar al amigo o denigrar al competidor: un gigantesco balcón en el

\footnotetext{
${ }^{1}$ Rheingold, Howard, Multitudes inteligentes, Gedisa, Barcelona 2004.
} 
que asomarse al universo de los demás para exhibirse ante ellos. Por eso son tan efectivos a la hora de convocar demostraciones públicas, porque combinan casi a la perfección las decisiones individuales con los espíritus gregarios.

La relevancia de estas movilizaciones populares, espontáneas o provocadas, palidece si se la compara con la influencia global de las redes sociales, de las que se benefician. La creación de estas comunidades virtuales equivale en cierta forma a la de la Convención en la Revolución Francesa. Cabe preguntarse entonces si será premonitoria de las medidas destinadas a implantar el Terror. Como en todo proceso revolucionario, sus promotores e integrantes tienden a dividirse en dos bandos: los moderados, que pretenden orientar los cambios garantizando la permanencia del pasado, y los radicales, dispuestos a acabar con todo lo que se les ponga por delante con tal de implantar el nuevo orden. En esta ocasión los moderados piensan que Internet es una gran conversación, un diálogo global; los radicales tienden a considerarlo una especie de asamblea permanente y soberana, fuera de la cual no existe nada que merezca reconocimiento. La cuestión está en saber si la muchedumbre puede ser inteligente, como dice Rheingold o si tiende a la masificación. La pretendida individualidad de los agentes del sistema perece en muchos casos en el aluvión impresionante en que se ha convertido Internet, capaz de anegar y arrasar todo cuanto encuentre a su paso. Ortega y Gasset, hace ahora un siglo, clamaba contra la aristofobia de las sociedades, en un deseo platónico de que estas fueran regidas por los mejores, y lamentaba la rebelión de las masas. Hoy estas se hacen presentes de manera virtual, aparentemente individualizada, en la red. ¿Se han adueñado del poder, verdaderamente, o nos encontramos solo ante un espejismo, una alucinación?

Quisiera ser explícito en este punto. Las nuevas tecnologías constituyen una gran oportunidad para el desarrollo humano. Su uso debe ser potenciado al máximo mediante la construcción de infraestructuras y la enseñanza adecuada de las habilidades precisas para servirse de ellas. Pero hay que desconfiar de quienes piensan que nos hallamos sin más ante un fenómeno de liberación de nuestra especie, capaz ahora de expresarse libremente como nunca antes lo hizo. La sociedad de la información está produciendo y producirá grandes beneficios pero también conlleva amenazas no pequeñas, lo que nos obliga a plantearnos de manera consciente y sin miramientos la capacidad de nuestras instituciones, nuestros líderes y nuestros referentes sociales para controlar y dirigir el cambio que se está produciendo. Dicha habilidad para orientar nuestro destino es lo que distingue a la civilización de la barbarie. 
En cualquier caso, la condición primera para dirigir un cambio es no resistirse a él. En este que ahora nos ocupa, cualquier cosa es posible menos volver al pasado. Es ya un lugar común esa pregunta popular entre nosotros: ¿Te acuerdas de cómo era la vida cuando no existían teléfonos celulares? Hace de eso apenas dos décadas y hoy parece ya que nada o casi nada de lo que hacemos puede llevarse a cabo sin ellos; son tan importantes para nuestras vidas como el aire que respiramos. Las tecnologías de la información han depositado una gran cantidad de poder de decisión en las gentes. Pero la suposición de que el poder como tal va a ser ejercido en adelante de manera casi directa por los ciudadanos resulta gratuita. La democracia es, entre otras cosas, la dispersión del poder que, por su propia naturaleza, tiende a concentrarse al tiempo que intenta penetrar todas las estructuras de la convivencia humana. La red no es ajena a esta tendencia y frente al sueño individualista que en algunos produce -puedo decir lo que quiera, cuando quiera y como quiera, para que todo el mundo me escuche- las estadísticas nos hablan de una situación muy diferente: más del cincuenta por ciento de los ciudadanos de los Estados Unidos se entera primero de las noticias por Google news, y el porcentaje sube al setenta por ciento en el caso de los que tienen menos de treinta y cinco años. Más del noventa por ciento de las búsquedas en Internet se realizan en Europa precisamente a través de Google. Y una red social como Facebook cuenta con ocjocientos millones de usuarios, lo que la convierte en un territorio virtual cuyos habitantes triplican la población de los propios Estados Unidos de América. Para no hablar de los millones y millones de twits que se distribuyen a diario. Nos encontramos ante una formidable concentración de poder mediático que paradójicamente ha sido construida de abajo arriba, no como un designio de los creadores de esas empresas, sino a través de aportaciones voluntarias de los usuarios, aunque provengan de un albedrío hipnotizado. La mayoría de estas operaciones a las que me refiero se lleva a cabo de forma automática. En la mayoría de los casos no son redacciones ni equipos de periodistas los encargados de seleccionar y jerarquizar las noticias, sino máquinas que siguen puntualmente los dictados de un algoritmo. Como consecuencia de ello, además, los datos privados de cientos de millones de personas son archivados, quizá para siempre, en los servidores de empresas que se declaran autónomamente a sí mismas únicos guardianes de la privacidad de susn usuarios. ¿Quién tiene el poder en esas circunstancias? ¿Quién la capacidad coactiva o manipuladora para hacer posible la dominación de los demás?

El desarrollo de Internet es, desde muchos puntos de vista, un desafío continuo a las formas de vida, los valores y las convenciones que han sustentado 
por décadas el consenso democrático. La intimidad y la propiedad intelectual son algunas de las piezas que ya se ha cobrado. En defensa de los gurús informáticos que han dado a luz esos nuevos imperios hay que decir que es difícil encontrar dolo alguno en sus propósitos. Gran parte de los avances en la sociedad de la información -a comenzar por el uso generalizado del correo electrónico- se ha producido de forma un tanto casual, y las más de las veces como un juego de adolescentes, en los sótanos y garajes de las familias de clase media americana o en los dormitorios universitarios. No es cierto que el universo por ellos creado no se someta a reglas, pero la norma que rige la convivencia en su seno no es ya la ley, sino el software. Mientras los gobernantes y responsables políticos y jurídicos se empeñen en ignorar este hecho, en operar como si no existiera, continuaremos indefensos ante los abusos y excesos que en nombre de su divinidad el algoritmo se cometen a diario.

Entre los nuevos comportamientos cívicos que este fenómeno está generando se encuentra eso que ha dado en llamarse periodismo ciudadano. Los usuarios se envían entre ellos todo tipo de material, frecuentemente imágenes captadas por su teléfonos celulares, con el objeto de establecer incipientes organizaciones parecidas a las periodísticas o interactuar con algunas de las ya existentes. Una buena parte de las informaciones que fluyen por la red, y no pocas de las más interesantes, se genera hoy por personas absolutamente ajenas a la profesión periodística y que nunca habían pensado dedicarse a nada parecido. Aunque ese no sea su objetivo, sino simplemente el comunicar a los demás algo que suponen solo ellos saben, están alterando el modo en el que se realizan las informaciones y la forma en que tiene lugar la comunicación política. Incluso el New York Times decidió fundar en la red una especie de escuela de periodismo ciudadano en donde por 175 dólares se enseña a quien lo desee a localizar y presentar una información, contrastar las fuentes y velar por la imparcialidad de los contenidos. Cabe preguntarse si nos hayamos en la antesala de la sustitución de buena parte de los periodistas profesionales por un elenco de aficionados con unas semanas de entrenamiento, cuyos salarios obviamente estarán a la altura de su limitada preparación. Internet es un mundo sin mediadores, como no sean estos los grandes monstruos que gobiernan el corazón del sistema, y hay ahora un gran número de improvisados reporteros que van desde la blogosfera a las redes sociales, multiplicando las producciones, individuales o colectivas, y mezclándose con grupos y movimientos sociales, activistas de todo tipo, cuya frenética aportación a la plétora de información que fluye por la red hace preguntarse por el futuro del periodismo profesional en ella. Los perio- 
distas, en palabras del fundador del diario La Reppublica, Eugenio Scalfari son gente que cuenta a la gente lo que le pasa a la gente. En definitiva, su tarea es la de mediadores entre la realidad y sus lectores u oyentes. ¿Pero qué hace un mediador en un mundo no intermediado? El cibernético es un espacio agitadísimo, lleno de debates, chismes, desinformación o información engañosa, un barullo y una mezcla en la que es difícil distinguir lo verdadero y lo falso, lo público y lo privado. Todo en él sucede además a gran velocidad en un campo virtual sin límites, en el que la conducta esencial es la interactividad entre los usuarios. Sería absurdo no reconocer que en ese universo los ciudadanos han adquirido poder y encuentran oportunidades antes desconocidas e imposibles de practicar. La diferencia de este cambio tecnológico frente a otros que lo precedieron es que anteriormente nos enfrentábamos a tecnologías de sustitución: nos facilitaban la forma de hacer las mismas cosas de manera más rápida, barata o eficiente. La sociedad digital se nutre en cambio de tecnologías de integración, que permiten hacer cosas nuevas, en absoluto imaginadas o imaginables antes de que dichas tecnologías existieran. De modo que el periodismo ciudadano, o la petulante información conversacional, significan más pluralidad y enriquecimiento del debate social. Aportan un cambio cualitativo a la manera de transmitir información y opiniones, permitiendo a los usuarios valorar las noticias, comentarlas y publicar sus propios comentarios. Pero eso no implica que sus contenidos sean mejores, y la experiencia demuestra que la mayoría de las veces no lo son. El periodismo ciudadano incide en cualquier caso, por propio derecho, en la capacidad productiva de los diarios que dedican importantes espacios de sus ediciones digitales a recoger y difundir esas experiencias. A cambio, padecemos una absoluta falta de rigor. Hay pocos reportajes y aún menos información que pase por controles rigurosos de verificación de los hechos o que estén sometidos al escrutinio editorial. Y casi ninguna compañía de Internet ha mostrado el potencial suficiente para generar los fondos necesarios a fin de ofrecer informaciones originales y profesionales, que sean fruto de una investigación rigurosa. Internet se desenvuelve, por lo demás, en una época en la que predominan las reyertas ideológicas y religiosas. Los fanáticos de cualquier cosa navegan por la red como pez en el agua, es su verdadero hogar: apoderarse ahora de la calle apenas sirve de nada si no se es capaz previamente de seducir on line las conciencias de los ciudadanos. Mientras tanto, la nueva soberanía de la que estos disfrutan en tanto que usuarios es transferida, la gran parte de las veces sin ellos saberlo, a instancias globales de poder, los señores de la red: Facebook, Google, Microsoft... 
En poco tiempo, de un desarrollo de los e-media basado primordialmente en los blogs, - antes lo estuvieron en las páginas web, en las alertas informativas, o en las noticias a la carta - hemos pasado a pretender que los medios del futuro, del presente ya, deben fundamentarse y construirse como remedos de las redes sociales, a fin de que los usuarios se relacionen entre sí, compartan ideas, contenidos, proyectos e intereses. Cobra enorme relevancia la gestión de los datos personales de dichos usuarios, a fin de poder convertir esos espacios compartidos no sólo en una fuente de información general, sino en sumidero de referencias particulares facilitadas por los propios usuarios. Las nuevas tecnologías acabarán con el absoluto dominio de las empresas tradicionales en tanto que agentes exclusivos de la venta de informaciones y de la difusión de opiniones plurales, pero ya han entronizado monopolios globales que están distorsionando por completo el mercado. Los periodistas profesionales, si no sabemos adaptarnos al cambio o fracasamos al querer encabezarlo, sufriremos el mismo desvarío y parecido destino que el que padecieron los monjes copistas una vez la imprenta comenzó a funcionar en Europa. Pero como antes decíamos los medios tradicionales han desempeñado, y siguen haciéndolo, un rol esencial en la articulación de la democracia y el funcionamiento de la política. Esta se define como la administración del espacio público compartido a partir de la existencia de la polis, la ciudad, y hasta la construcción de los estados-nación y de los organismos globales e internacionales. Hoy ese espacio público es el territorio privilegiado de la red. Ningún otro puede albergar de modo simultáneo tan gran número de individuos y tan relacionados entre sí. Los políticos, los estadistas, los artistas, los creadores, los líderes sociales, no han sacado todavía suficientemente las consecuencias de ello. Parece que solo lo han hecho los comerciantes

Desde el nacimiento de la red en 1989 la sociedad de la información ha recorrido un largo y rápido camino, desarrollándose a pasos agigantados en todo el mundo. Con la expansión del correo electrónico tuvimos la web 1.o, orientada a la comunicación y al comercio. Sufrió la primera crisis a principios de este siglo, cuando el estallido de la burbuja provocó la quiebra de las puntocom. Enseguida surgió la web 2.0 constituida por las redes sociales, basada en la comunicación entre personas y comunidades. Al tiempo se desarrollaron los portales que permiten el disfrute en línea de todo tipo de contenidos, empaquetados por nuevos intermediarios que no se someten a control ni jerarquía conocidos, e intercambian archivos gratuitos realizados por otras personas que han invertido su tiempo y su dinero. Se implantó el principio de gratuidad en el funcionamiento del sistema y se destruyeron 
los modelos de negocio tradicionales. La industria musical primero, la de la información ahora, han visto derrumbarse verdades que parecían inmutables y nos hallamos todos, gobiernos y ciudadanos, inmersos en un discurso apocalíptico sobre el futuro de los medios. Los magnates de la comunicación debaten, a veces entre estertores, sobre la conveniencia o no de cobrar por la distribución de diarios y revistas en la red. De habitual su respuesta es errónea, porque lo que está equivocado es la interrogante. La pregunta pertinente es, si cuando la gratuidad de los contenidos se generalice a escala mundial, se acabará la información contrastada y fiable, el conocimiento no adulterado y las películas y música de calidad. Cuestión añadida consiste en saber qué tenemos que hacer para que eso no suceda.

La red se ha instalado en nuestras vidas: imposible imaginar que podamos prescindir de ella para buscar y obtener información, acceder al conocimiento, investigar en no importa qué especialidad, controlar la salud pública, implementar procesos educativos, comprar productos o realizar transacciones. Estamos ante un cambio social y cultural de incalculables dimensiones que conlleva nuevos valores y actitudes y exige nuevas pautas de comportamiento. En lo que se refiere a nuestro oficio tiendo a imaginar que debemos esforzarnos por crear una especie de ecosistemas informativos en los que lo virtual y lo real, lo digital y lo analógico, sean capaces de interactuar y del que se pueda entrar y salir con comodidad, con tranquilidad y sin estar sometido a más presión que la del interés, el placer, la emoción o la curiosidad de cada cual. Si somos capaces de hacer que eso suceda, sabremos también descubrir la forma de financiarlo por los propios usuarios. Ya sé que esto puede sonar a utopía revolucionaria, pero el que las lecturas de la Historia me aconsejen desconfiar de las revoluciones no significa que hayan dejado de gustarme.

La realidad virtual puede ser en ocasiones tan verdadera como la realidad real. Y a mí me gusta imaginar el universo de Internet como el poeta del pueblo, Miguel Hernández, ensoñaba su casa desde la prisión en que estaba encerrado: "Las puertas, de par en par, y en el fondo, el mundo entero".

Coimbra, Diciembre, 2012. 